www.jmscr.igmpublication.org

Impact Factor (SJIF): 6.379

Index Copernicus Value: 71.58

ISSN (e)-2347-176x ISSN (p) 2455-0450

crossrefDOI: https://dx.doi.org/10.18535/jmscr/v6i6.71

Journal Of Medical Science And Clinical Research

IGM Publication

An Official Publication of IGM Publication

\title{
Relation between Frontal Sinus Morphology and the Cervical Vertebral Maturation for the Evaluation of the Skeletal Maturity among Solapur Population: A Cross Sectional Study
}

\author{
Authors \\ Dr Vandana R. Dodmani ${ }^{1 *}$, Dr Sunilkumar P. ${ }^{2}$, Dr Chandrashekhar Gouda B. Patil ${ }^{3}$, \\ Dr Akash B. Lavate ${ }^{4}$, Dr Sneha V. Hoshing ${ }^{5}$, Dr T. Rajesh Singh ${ }^{6}$ \\ Dr Sukumar V. Lipare ${ }^{7}$ \\ ${ }^{1,7}$ Post Graduate Student, Department of Orthodontics and Dentofacial Orthopedics, Pandit Deendayal Upadhyay \\ Dental College, Solapur \\ ${ }^{2}$ Professor and HOD, Department of Orthodontics and Dentofacial Orthopedics, Pandit Deendayal Upadhyay Dental \\ College, Solapur \\ ${ }^{3.4}$ Reader, Department of Orthodontics and Dentofacial Orthopedics, Pandit Deendayal Upadhyay Dental College, \\ Solapur \\ ${ }^{5}$ Senior lecturer, Department of Orthodontics and Dentofacial Orthopedics, Pandit Deendayal Upadhyay Dental \\ College, Solapur \\ ${ }^{6}$ Reader, Department of Oral Medicine and Radiology, College of Dental Sciences Amargadh, Gujrat. \\ *Corresponding Author
}

Dr Vandana R. Dodmani

C/O Dr. Raghuvir B. Dodmani, 56, Railway lines, Wonderland Appartments, Flat no. 12, Solapur- 413001

Contact no. 8999006378

\begin{abstract}
Introduction: There are various methods to evaluate the developmental status of a patient. But still the hand wrist and cervical vertebral maturity remains the standard for the evaluation of skeletal maturity. The aims of this study were to evaluate the association between frontal sinus morphology and cervical vertebral maturation for the assessment of skeletal maturity.

Methods: A study was performed on the pretreatment lateral cephalograms of 30 subjects aged 8 to 21 years. The sample was divided into 6 groups based on the cervical vertebral maturation stages. The frontal sinus index was calculated by dividing the frontal sinus height and width, and the cervical stages were evaluated on the same radiograph. The Kruskal-Wallis test was applied to compare frontal sinus index values at different cervical stages, and the post hoc Dunnett T3 test was applied to compare frontal sinus index values between adjacent cervical stages for each sex. A P value of \#0.05 was considered statistically significant.

Results: The height and width of the frontal sinus were significantly larger in the male subjects than in the females. A significant association was found between the frontal sinus height and width and cervical stages $(P$ \#0.001) in both sexes. Similarly, a weak negative correlation was found between the sinus index and the cervical stages in male subjects), whereas no correlation was found in female subjects. However, the post hoc analysis showed that the values of the sinus index were comparable between any 2 adjacent cervical stages.

Conclusions: The frontal sinus index could not differentiate between the pre pubertal, pubertal and postpubertal stages. Therefore, it cannot be used as a reliable maturity indicator.

Keywords: lateral cephalogram, frontal sinus, cervical vertebral stages.
\end{abstract}




\section{Introduction}

The assessment of growth potential during the preadolescent or adolescent growth spurt has considerable influence on orthodontic diagnosis and treatment planning as well as outcome and stability. Similarly, the analysis of growth plays a vital role in the orthodontic decision making process. Skeletal maturation refers to the degree of development of ossification in bone. Size and maturation can vary independently of each other. Skeletal maturation is more closely related to sexual maturity than to stature. ${ }^{1-5}$

Chronologic age fails to provide an accurate diagnosis of the growth status of a child, since children of the same chronologic age usually have variable degrees of skeletal maturation. ${ }^{6}$ The classic parameters include changes in body height and weight, appearance of secondary sexual characteristics, chronologic age, tooth mineralization and calcification and skeletal maturation. ${ }^{7}$

The ossification of bones of the hand and wrist is considered the most accurate method; but, it requires an additional exposure of radiation, leading to ethical limitations. ${ }^{8,9}$ To reduce this radiation exposure, Lamparski evaluated the maturation of the cervical vertebrae on lateral cephalograms, and it was reported that cervical vertebral maturation correlated with the skeletal maturation of a child. ${ }^{10-13}$

The cervical vertebral maturation method is currently the most widely used method to assess the growth status of a child. However, it carries certain limitations; eg, difficulty in classifying cervical vertebral bodies 3 and 4 as trapezoidal, rectangular ,horizontal, square or rectangular vertical. Moreover, division of the pubertal growth spurt into discrete stages is inappropriate to describe a continous phenomenon. ${ }^{14,15}$

Changing morphology of the frontal sinus during the adolescecnt growth spurt is a new method of assessing the developmental status of a child. Even though there are several reports on the development of the frontal sinus, few studies have investgated the relationship of the frontal sinus with the other growth parameters. Ruf and Pancherz evaluated frontal sinus morphology on lateral cephalograms and reported a well - defined pubertal growth spurt in the enlargement of the frontal sinus. ${ }^{16-18}$

\section{Material and Methods}

Data were collected retrospectively from the pretreatment lateral cephalograms of orthodontic patients visiting the department of orthodontic and Dentofacial orthopedics, P.D.U Dental College, Solapur. The total sample consisted of 30 subjects, uniformly divided into 6 cervical stages having equal numbers of males and females. Subjects with good-quality standardized pretreatment lateral cephalograms and aged between 8 and 21 years were included in the study. Subjects with a history of sinus-related pathologies; any craniofacial anomaly, syndrome, trauma, or surgery involving the frontal sinus or the cervical vertebrae; or any systemic disease affecting growth and development were excluded from the study. The lateral cephalogram was taken on the Digital Cephalostat machine Carestream CS 8000c. The frontal sinus height and width measurements were analyzed using the method of Ertuk. $^{22}$ The cephalogram was oriented with the sella-nasion line horizontal. The maximum height and width of the sinus were measured as shown in (Fig 1). The ratio between the frontal sinus height and width was calculated for each patient and was regarded as the sinus index. The cervical vertebral maturation stages were assessed on the same lateral cephalogram using the method of Baccetti et al $^{23}$ (Fig 2). The Shapiro-Wilk test was used to check the normality of the data, which showed a nonnormal distribution; hence, nonparametric tests were applied. The Mann-Whitney U test was used to compare frontal sinus measurements in both sexes. Comparisons between frontal sinus measurements among the different cervical stages were made using the Kruskal-Wallis test. The post hoc Dunnett T3 test was applied to compare frontal sinus index values at adjacent cervical stages. The Kendall tau-b correlation was used to 
determine the correlation between frontal sinus measurements and cervical stages in the sexes. $\mathrm{P}$ value of $\# 0.05$ was considered statistically significant.

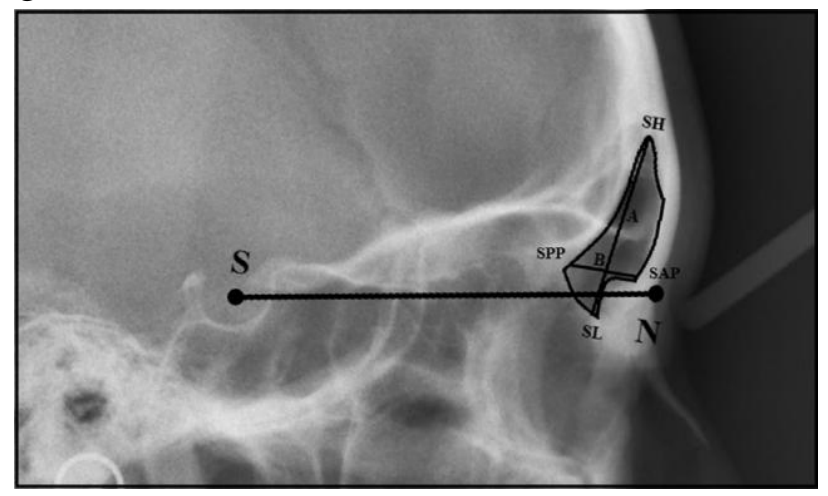

Fig 1 Assessment of the frontal sinus morphology on a lateral cephalogram using the method of Ertuk.22 SH, The highest point on the frontal sinus; SL, the lowest point on the frontal sinus; A, line joining SH and SL denoting maximum frontal sinus height; SPP, posterior point on the frontal sinus; SAP, anterior point on the frontal sinus; B, line joining SPP and SAP denoting the maximum frontal sinus width perpendicular to line $\mathrm{A} ; \mathrm{S}$, anatomic center of sella turcia; $\mathrm{N}$, deepest point in the midline at the frontonasal suture.

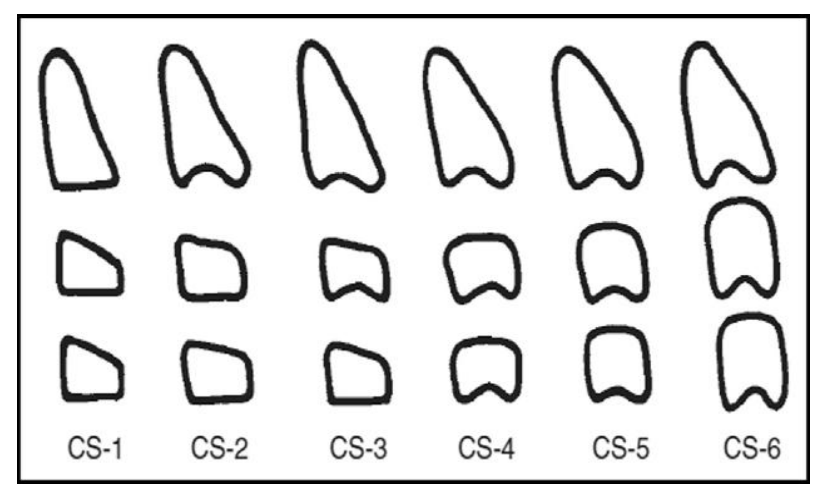

Fig 2. Cervical vertebral maturation stages according to the method of Baccetti et al. ${ }^{23} \mathrm{CS} 1$, The inferior borders of the bodies of all cervical vertebrae are flat; the superior borders are tapered from posterior to anterior; CS 2, a concavity develops in the inferior border of the second vertebrae; the anterior vertical height of the bodies increases; CS 3, a concavity develops in the inferior border of the third vertebrae; 1 vertical body has a trapezoidal or wedge shape; CS 4, a concavity develops in the inferior border of the fourth vertebrae; concavities in the lower border of the fifth and sixth vertebrae are beginning to develop; the bodies of all cervical vertebrae are rectangular; CS 5, concavities are well defined in the lower borders of the bodies of all cervical vertebrae; the bodies are nearly square, and the spaces between the bodies are reduced; CS 6, all concavities have deepened; the vertebral bodies are now higher than they are wide.

\section{Results}

The frontal sinus height, width, and index were compared between the sexes; this showed significant differences, with males having greater sinus heights and widths, and females having greater values of the sinus index (Table 1). Further statistical analyses were performed separately for each sex. Significant differences were found in frontal sinus heights and widths at different cervical stages in each sex, whereas a statistically significant $(\mathrm{P} \# 0.001)$ difference between the frontal sinus index at different cervical stages was found in male subjects only (Table 2). To further validate our results and to see whether these differences were present between adjacent cervical stages, the post hoc Dunnett T3 test was applied. This showed no significant difference in the frontal sinus index at adjacent cervical stages (Table 3). The correlations between frontal sinus measurements and cervical stages were evaluated between the sexes; these showed a weak negative correlation in males and an insignificant correlation in the female sample.

Table 1 Comparison of frontal sinus measurements

\begin{tabular}{|c|c|c|c|}
\hline $\begin{array}{c}\text { Frontal Sinus } \\
\text { Parameter }\end{array}$ & $\begin{array}{c}\text { Frontal Sinus } \\
\text { Height(mm) }\end{array}$ & $\begin{array}{c}\text { Frontal Sinus } \\
\text { Width(mm) }\end{array}$ & $\begin{array}{c}\text { Frontal Sinus } \\
\text { Index }\end{array}$ \\
\hline Female & 24.4 & 9.46 & 2.57 \\
\hline Male & 28.66 & 12.9 & 2.22 \\
\hline $\mathrm{P}$ & 0.005 & $<0.001$ & $<0.001$ \\
\hline
\end{tabular}


Table 2 Comparison of frontal sinus measurements at the different cervical stages

\begin{tabular}{|l|c|c|c|c|c|c|c|c|}
\hline Cervical Stages & Sex & CS1 & CS2 & CS3 & CS4 & CS5 & CS6 & P \\
\hline Frontal Sinus Height(Mm) & Male & 17.66 & 23.3 & 25.2 & 30.39 & 32.51 & 33.17 & $<0.001$ \\
\cline { 2 - 9 } & Female & 19.91 & 22.12 & 24.2 & 28.32 & 29.94 & 31.32 & $<0.001$ \\
\hline \multirow{2}{*}{ Frontal Sinus Width $(\mathrm{mm})$} & Male & 7 & 9.51 & 10.34 & 11.64 & 12.8 & 13 & $<0.001$ \\
\cline { 2 - 9 } & Female & 7.12 & 7.83 & 8.03 & 8.57 & 10.62 & 10.85 & $<0.001$ \\
\hline \multirow{2}{*}{ Frontal Sinus Index } & Male & 2.5 & 2.45 & 2.43 & 2.61 & 2.53 & 2.41 & $<0.001$ \\
\cline { 2 - 9 } & Female & 2.79 & 2.82 & 3.01 & 3.30 & 2.81 & 2.88 & $<0.001$ \\
\hline
\end{tabular}

Table 3 Comparisn of frontal sinus index between adjacent cervical stages

\begin{tabular}{|c|c|c|c|c|c|c|}
\hline & $\begin{array}{l}\text { Start of Pubertal } \\
\text { Growth Spurt }\end{array}$ & \multicolumn{2}{|c|}{ Pubertal Growth Peak } & \multicolumn{2}{|c|}{ End Of Pubertal Growth Spurt } \\
\hline & & $\begin{array}{c}\text { CVM I Vs } \\
\text { CVM } \\
\text { II }\end{array}$ & $\begin{array}{l}\text { CVM II Vs CVM } \\
\text { III }\end{array}$ & $\begin{array}{l}\text { CVM III Vs CVM } \\
\text { IV }\end{array}$ & $\begin{array}{l}\text { CVM IV Vs } \\
\text { CVM V }\end{array}$ & $\begin{array}{c}\text { CVM V Vs } \\
\text { CVM } \\
\text { VI }\end{array}$ \\
\hline \multirow{3}{*}{$\begin{array}{l}\text { Frontal } \\
\text { index }\end{array}$} & & $\mathrm{P}$ & $\mathrm{P}$ & $\mathrm{P}$ & $\mathrm{P}$ & $\mathrm{P}$ \\
\hline & Male & 0.444 & 0.976 & 0.873 & 0.839 & 0.670 \\
\hline & Female & 0.973 & 1.000 & 1.000 & 0.988 & 0.988 \\
\hline
\end{tabular}

Table 4 Correlation between frontal sinus measurements and cervical stages

\begin{tabular}{|l|c|c|c|}
\hline Variable & Sex & Correlation with cervical stages & P value \\
\hline Frontal sinus height & Male & 0.55 & $<0.01$ \\
\hline & Female & 0.49 & $<0.01$ \\
\hline Frontal sinus width & Male & 0.58 & $<0.01$ \\
\hline & Female & 0.41 & $<0.01$ \\
\hline Frontal sinus index & Male & -0.21 & $<0.01$ \\
\hline & Female & -0.15 & $<0.01$ \\
\hline
\end{tabular}

\section{Discussion}

The skeletal maturity can be assessed by using frontal sinus morphology frontal sinus width, frontal sinus height but instead of taking individual height or width it is better to calculate the frontal sinus index by dividing the height by width, since the size of the frontal sinus may vary according to a patient's physical size and sex.24 The frontal sinus height increases with cervical stages in both the sexes. Sinus height is greater in males. The studies of Hanson and Owsley and Pond et al shows similar findings. ${ }^{25,26}$ The width of the frontal sinus also increases from cervical stages 1 to 6 . The increase in width is greater in males than in females. These findings are similar with those of Ruf and Pancherz. ${ }^{20,21}$ They reported that the enlargement in the width of the frontal sinus could be considered as a maturity indicator, but their sample consisted of male subjects only. The sinus index is greater in females than the males. (table 1). The study performed by Patil and Revankar evaluated the correlations between the frontal sinus index and the ossification of the middle phalanx of the third finger and failed to find a significant correlation. The frontal sinus index was not a reliable maturity indicator. ${ }^{27}$

The frontal sinus starts to develop in the fourth or fifth week of gestation, continues its growth during childhood, and reaches its final size and form in early adulthood.28 As the pneumatization of the frontal sinus increases, it becomes radiographically evident by the age of 8 years. ${ }^{29}$ The growth of the frontal sinus is synchronous with craniofacial growth, and its enlargement is based on the expanding braincase. ${ }^{30}$ The enlargement of the frontal sinus exhibits a welldefined adolescent growth spurt, which is on average 1.4 years after the peak in body height. ${ }^{28}$ This study is done with minimum sample size so to get statistically significant values we ought to increase the samples. 


\section{Conclusion}

1) There is association between the frontal sinus height and width cervical maturation stages in both gender.

2) But the frontal sinus index could not differentiate between the pre pubertal, pubertal and postpubertal stages.

3) Hence presently also cervical vertebral maturation is the standard to evaluate the skeletal maturity for diagnosis and treatment planning.

\section{References}

1. Tanner JM. Growth at adolescence an introduction. In: Carlson D, Ribbens K, eds. Monograph 20, Craniofacial Growth Series. Ann Arbor: Center for Human Growth and Development, University of Michigan, 1987.

2. Scammon R. The first seriatim study of human growth. Am J Phys Anthropol 1927;10:328-35.

3. Tanner JM. A history of the study of human growth. Cambridge: Cambridge University Press, 1981.

4. Falkner F, Tanner JM. Human growth. Vols 1-3. New York: Plenum Press, 1988.

5. Poznanski A. The hand in radiologic diagnosis. Vol. 1.2nd ed. Philadelphia: WB Saunders, 1976.

6. Finkel D, Whitfield K, McGue M. Genetic and environmental influences on functional age: a twin study. J Gerontol B Psychol Sci Soc Sci 1995;50:104-13.

7. Malgorzata M, Tiziano B. Duration of pubertal peak in skeletal Class I and Class III. Angle Orthod 2010;80:54-7.

8. Tarvade SM, Ramkrishna S. Skeletal maturity indicators. $\mathbf{J}$ Orthod Res 2015;3:158-61

9. Houston WJ, Miller JC, Tanner JM. Prediction of the timing of the adolescent growth spurt from ossification events in hand-wrist films. Br J Orthod 1979;6:14552.
10. Houston WJ. Relationships between skeletal maturity estimated from handwrist radiographs and the timing of the adolescent growth spurt. Eur J Orthod 1980;2:81-93.

11. Canavese F, Charles YP, Dimeglio A. Skeletal age assessment from elbow radiographs. Review of the literature. Chir Organi Mov 2008; 92:1-6.

12. Abdel-Kader HM. The reliability of dental $\mathrm{X}$-ray film in assessment of MP3 stages of the pubertal growth spurt. Am J Orthod Dentofacial Orthop 1998;114:427-9.

13. Madhu S, Hegde AM, Munshi AK. The developmental stages of the middle phalanx of the third finger (MP3): a sole indicator in assessing the skeletal maturity? J Clin Pediatr Dent 2003;27:149-56.

14. Lamparski DG. Skeletal age assessment utilizing cervical vertebrae [thesis]. Pittsburgh, Pa: University of Pittsburgh; 1972.

15. Hassel B, Farman AG. Skeletal maturation evaluation using cervical vertebrae. Am J Orthod Dentofacial Orthop 1995;107:5866.

16. Franchi L, Baccetti T, McNamara JA. Mandibular growth as related to cervical vertebral maturation and body height. Am J Orthod Dentofacial Orthop 2000; 118:335-40.

17. Wong RW, Alkhal HA, Rabie AB. Use of cervical vertebral maturation to determine skeletal age. Am J Orthod Dentofacial Orthop 2009;136:484.e1-6.

18. Nestman TS, Marshall SD, Qian F, Holton N, Franciscus RG, Southard TE. Cervical vertebrae maturation method morphologic criteria: poor reproducibility. Am J Orthod Dentofacial Orthop 2011;140:182-8.

19. Gabriel DB, Southard KA, Qian F, Marshall SD, Franciscus RG, Southard TE. Cervical vertebrae maturation method: 
poor reproducibility. Am J Orthod

Dentofacial Orthop 2009;136: 478.e1-7.

20. Ruf S, Pancherz H. Frontal sinus development as an indicator for somatic maturity at puberty? Am J Orthod Dentofacial Orthop 1996;110:476-82.

21. Ruf S, Pancherz H. Can frontal sinus development be used for the prediction of skeletal maturity at puberty? Acta Odontol Scand 1996;54:229-34.

22. Ertuk N. Fernrontgenuntersuchungen uber die entwicklung der stirnhohle. Fortschr Kieferothop 1968;29:245-8.

23. Baccetti T, Franchi L, McNamara JA Jr. The cervical vertebral maturation (CVM) method for the assessment of optimal treatment timing in dentofacial orthopedics. Semin Orthod 2005; 11:11929.

24. Shapiro R, Schorr S. A consideration of the systemic factors that influence frontal sinus pneumatization. Invest Radiol 1980;15:191-202.

25. Hanson CL, Owsley DW. Frontal sinus size in Eskimo populations. Am J Phys Anthropol 1980;53:251-5.

26. Pond_e JM, Andrade RN, Via JM, Metzger P, Teles AC. Anatomical variations of the frontal sinus. Int $\mathbf{J}$ Morphol 2008;26:803-8.

27. Patil AA, Revankar AV. Reliability of the frontal sinus index as a maturity indicator. Indian J Dent Res 2013;24:523.

28. Duque CS, Casiano RR. Surgical anatomy and embryology of the frontal sinus. In: Stilianos E, Kountakis B, Wolfgang A, editors. The frontal sinus. Berlin, Germany: Springer; 2005. p. 21-31.

29. Dolan KD. Paranasal sinus radiology, part 1A: introduction and the frontal sinuses. Head Neck Surg 1982;4:301-11.

30. Brown WA, Molleson TI, Chinn S. Enlargement of the frontal sinus. Ann Hum Biol 1984;11:221-6. 